\title{
Evaluation of Uterotonic Activity of Hydro-ethanolic Extract of Unripe Fruit of Carica papaya Linn using Wistar Albino Rats
}

\author{
Praveena $\mathbf{P}^{1^{*}}$, Jethinlalkhosh $\mathrm{JP}^{1}$, Victor Arokia Doss ${ }^{3}$ \\ ${ }^{1}$ Research and Development Centre, Bharathiar University, Coimbatore -641046, Tamil Nadu, INDIA. \\ ${ }^{2}$ Department of Biochemistry, P S G College of Arts and Science, Coimbatore - 641014, Tamil Nadu, INDIA.
}

\begin{abstract}
Objective: This study was undertaken due to the popular belief in most of the Asian countries that the unripe fruit of Carica papaya $L$ if eaten during early months of pregnancy can lead to miscarriage. The aim of the present study was to screen the effect of administration of hydroethanolic extract of unripe fruit of Carica papaya L (EECP). Materials and Methods: Female pregnant rats were taken and divided into various groups viz; Groupl (control); Groupll (200mg/kg p.o EECP);Groupll (400mg/kg p.o EECP; and Group IV(Ethinyl estradiol $0.02 \mathrm{mg} / \mathrm{kg}$.p.o) for the experiments. After oral administration of the extract laparotomy was performed and uteri were examined to determine the number of implantation sites. At the end of the experiment all the rats in each group were sacrificed. Haematological and biochemical parameters were determined. Hormone level modulation was also analyzed. Results: The present study suggested that there are significant variations in the biochemical parameters. The hormonal stability had also been altered which had in turn led to the termination of pregnancy. Conclusion: The study revealed that hydroethanolic extract inhibited the process of implantation. The loss of implantation caused may be due to antizygotic, blastocytotoxicity of the extract.
\end{abstract}

Key words: Carica papaya L., Antifertility, Antizygotic, Alkaloid.

\section{INTRODUCTION}

Plant based concoctions has become a significant element of various medical systems around the world. Majority of the plants studied have shown effective medicinal values. Traditional knowledge is now being studied and understood with respect to its foundation. Population explosion has created a considerable setback in the economic growth development in developing countries thus demanding an immediate betterment of new potential contraceptives. ${ }^{1}$ Studies have highlighted the unmet demand for safe, inexpensive, and acceptable contraceptives to avoid unwanted pregnancies and resultant abortions. ${ }^{2,3}$ Although a wide variety of synthetic contraceptive agents are available, these cannot be used continuously due to their severe side effects. ${ }^{4,5}$ The control of human fertility in the sense of its limitation has become one of the most important social and medical problems confronting mankind today. Contraception is literally the prevention of conception, but is generally taken to mean prevention of pregnancy. With any method of contraception, there is some risk of pregnancy. ${ }^{6}$ Termination of pregnancy is a medically directed miscarriage prior to independent viability, using pharmacological or surgical means. The moral and legal aspects of abortion are subject to intense social debate in many parts of the world. In the recent years efforts are being made to identify herbal contraceptives which are biologically safe and also cost effective. Certain herbs should never be used in pregnancy. As a general rule, no medications or herbs should be used in the first trimester of pregnancy, unless medically indicated.
Submission Date: 24-03-2017; Revision Date: 31-05-2017; Accepted Date: 25-09-2017

DOI: 10.5530/ijper.51.4s.90 Correspondence: Praveena $P$,

Assistant Professor, Department of Biotechnology Engineering, Sahrdaya College of Engineering and Technology, Thrissur, Kerala, India.

Phone no: +918589898963; E-mail: praveenapadmam@ gmail.com

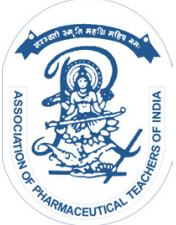

www.ijper.org 
One exception to this rule is ginger root (Zingiber officinale), which has been used for centuries worldwide for morning sickness. ${ }^{7}$

Carica papaya Linn (C.papaya) belonging to the family of Caricaceae, is widespread throughout the tropical and subtropical areas. It is commonly known as papaya in English, papita in Hindi and koppanga in Malayalam. The plant recognized by its weak and usually unbranched soft stem yielding copious white latex and crowded by a terminal cluster of large and long stalked leaves, is rapidly growing and can grow up to $20 \mathrm{~m}$ height. It is cultivated for its fruits. Papaya as in many fruits and vegetables is rich in antioxidant compounds. The fruit contains a high level of vitamin $\mathrm{C}$, carotenoids such as $\beta$-carotene and lycopene. Several studies have proven that C.papaya $\mathrm{L}$ has commendable medicinal properties. Papain is a proteolytic enzyme which finds numerable industrial uses. It is used in meat tenderizes and chewing gums. The leaves are used for treatment of malaria, dengue and jaundice. Both leaves and fruits of C.papaya possess medicinal properties like anti-inflammatory hypoglycaemic, anti-fertility, hepatoprotective, wound healing, antihypertensive and antitumor activities. ${ }^{8}$ Vegetable abortifacients have been in use for a long time in many countries and were or are still employed in rural areas of India. ${ }^{9}$ Evidences from several studies suggest that the unripe fruits of C.papaya have antifertility properties. Consumption of ripe papaya during pregnancy is not dangerous, however unripe and semi ripe papaya contain high amount of latex that produces marked uterine contraction that could be unsafe during pregnancy. ${ }^{10,11}$ The crude papaya latex contains a uterotonic principle consisting of a combination of enzymes, alkaloids, flavanoids and other substances, which evoke sustained contractions of the uterus by acting mainly on the alpha adrenergic receptor population of the uterus at different stages. ${ }^{12}$ Papaya leaves has been seen as a potential source of useful food and drug items. The presence of alkaloids is being effectively used as an anti-malarial agent. ${ }^{13,14}$ According to the book 'Nature cure for cancer' there are many reports that cancer sufferers have been healed by drinking papaya leaf concentrate ${ }^{15}$. Medical research in animals has confirmed the contraceptive and abortifacient capability of papaya, and also found that papaya seeds have contraceptive effects in adult male langur monkeys, possibly in adult male humans as well. Unripe papaya is especially effective in large amounts or high doses. ${ }^{16}$ Papaya is not teratogenic and will not cause miscarriage in small, ripe amounts. Phytochemicals in papaya may suppress the effects of progesterone. Oral or intraperitoneal administration of various formulations of the papaya plant during different phases of pregnancy was reported to have exerted a number of effects on pregnancy and embryonic development, such as anti implantation activity, increased post implantation loss, and embryo toxicity. Researchers have noted that unripe papaya latex acts like prostaglandin and oxytocin, which the body makes to, start labor. Synthetic prostaglandin and oxytocin are commonly used to start or strengthen labor contraction. ${ }^{10}$ The same extract produced antifertility effect in a dose dependent manner and the contraceptive effect manifested a definite period of time.

\section{MATERIALS AND METHODS \\ Plant collection and identification}

The unripe fruits of C.papaya $\mathrm{L}$ were collected from in and around Kodakara, Thrissur, Kerala. They were identified and certified by the Taxonomist, Botanical Survey of India (BSI), Coimbatore, Tamil Nadu, India (Plant identification no: BSI/SRC/5/23/2013-14/ Tech/683).

\section{Plant Extraction}

Crude plant extracts were extracted by Soxhlet extraction method. About 100 grams of plant material was uniformly packed into a thimble and extracted with 350 $\mathrm{ml}$ of $50 \%$ ethanol as solvent. The process of extraction continued till the solvent in siphon tube of an extractor became colourless. The solvent extract was filtered and dried using rotary evaporator. This ethanolic fraction of Carica papaya L (EECP) was taken for further studies.

\section{Phytochemical analysis}

The extract was subjected to various qualitative phytochemical analyses. The presence of carbohydrates, proteins, ${ }^{17}$ fats, steroids, ${ }^{18}$ alkaloids, ${ }^{19-21}$ flavanoids, phenols, ${ }^{22}$ saponins, glycosides and tannins were tested. The quantitative phytochemical analyses were also conducted.

\section{HPLC Analysis}

The extract was subjected to High Pressure Liquid Chromatography. For determining the flavanoid, $1 \mathrm{mg}$ of the extract was dissolved in HPLC grade methanol(mobile phase).Quercetin was used as the standard. The flow rate was $0.5 \mathrm{ml}$ per minute and the flavanoid was monitored at $272 \mathrm{~nm}$. For determining the alkaloid, mobile phase was acetonitrile: water (50:50). Caffeine was used as the standard. The flow rate was $1.0 \mathrm{ml}$ per minute and the alkaloid was monitored at $271 \mathrm{~nm}$. The HPLC analysis was performed using Agilent 1260 Infinity Quaternary Liquid Chromatography, column ZORBAX Eclipse Plus C18 (4.6x250 mm, 5 um). 


\section{EVALUATION OF UTEROTONIC ACTIVITY Experimental animals}

Healthy female Wistar albino rats weighing about 150-200g were procured from animal house, K.M.College of Pharmacy, Uthangudi, Madurai. They were housed in polypropylene cages $(38 \mathrm{~cm} \times 23 \mathrm{~cm} \times 10 \mathrm{~cm})$ with not more than six animals per cage and maintained under standard environmental conditions $(14 \mathrm{~h}$ dark $/ 10 \mathrm{~h}$ light cycles; temp $25 \pm 2{ }^{\circ} \mathrm{C}$; $35-60 \%$ humidity, air ventilation) and were fed with standard pellet $\operatorname{diet}(\mathrm{M} / \mathrm{s}$. Hindustan Lever Ltd., Mumbai, India) and fresh water ad libitum. The animals were acclimatized to the environment for two weeks prior to experimental use. Animals were fasted over night before the experimental schedule, but had free access for water ad libitum. The entire study was approved by the Institutional Animal Ethical Committee (IAEC) which is certified by the Committee for the Purpose of Control and Supervision of Experiments on Animals (CPCSEA), Ministry of Social Justice and Empowerment, Government of India (IAEC no.:661/02/c/CPCSEA).

\section{Acute toxicity study}

Acute toxicity study was performed according to OECD guidelines 425 (Organization of Economic Co-Operation and Development). ${ }^{23}$ The rats were fasted over-night and provided with water ad libitum. Following the period of fasting, the animals were treated with the test extract at the dose of $2000 \mathrm{mg} / \mathrm{kg}$ (EECP) body weight.

\section{Uterotonic activity study}

Vaginal smear of each female rat was monitored daily and rats with normal estrous cycle were selected and anti implantation study was conducted ${ }^{24}$. Rats found in proestrus phase of cycle were caged with males of proven fertility, in the ratio of 2:1 and examined the following morning for evidence of copulation. Rats exhibiting thick clumps of spermatozoa in their vaginal smears were separated and that day was designated as day 1 of pregnancy and the rats were divided into four groups containing six rats in each group. From day 1 all the rats were given specific extracts. Group I (control) received the vehicle ( $1 \%$ tween 80 p.o).Groups II and III received EECP at $200 \mathrm{mg} / \mathrm{kg}$ and EECP at $400 \mathrm{mg} / \mathrm{kg}$ of body weight respectively. Group IV received a standard reference drug Ethinyl estradiol (0.02 mg/kg, p.o). On day 10 laparotomy was performed under ketamine anesthesia and sterile conditions. The uteri were examined to determine the number of implantation sites. The abdomens were sutured and the animals were allowed to go on term. At the end of the experiment all the rats in each group were sacrificed and the blood was collected through cardiac puncture for studying haematological parameters and serum was separated for studying biochemical parameters.

\section{Study of alteration in hormone levels}

The effect of EECP on the stability of hormones essential for sustaining pregnancy viz; $\beta$-human Chorionic Gonadotropin ( $\beta$-hCG), progesterone and estradiol was screened. ${ }^{25}$ At the end of the experiment, all the rats in each group were sacrificed and the blood was collected through cardiac puncture and serum was collected for the study.

\section{Statistical analysis}

The results are expressed as mean \pm standard deviation (SD).Differences between groups were assessed by one way analysis of variance (ANOVA) using the Statistical Package of Social Sciences (SPSS, Version 16.0 for windows). The group means were compared by Duncan's Multiple Range Test (DMRT). Values were considered statistically significant when $\mathrm{p}<0.05$.

\section{RESULTS}

The solvent extraction of the unripe fruit of C.papaya was performed and $8.9 \mathrm{~g}$ of crude fraction was obtained. Phytochemical analysis was performed and the results are shown in Table 1. The results showed the presence of carbohydrates, protein, flavanoids, alkaloids, saponins, tannins, glycosides etc. Quantitative estimation of the phytochemicals were performed and are depicted in Figure 1. The bioactive were detected using quercetin and caffeine as standards respectively (Figure 2 and Figure 3).

\section{Acute toxicity study}

The study revealed that the EECP are found to be very safe up to $2000 \mathrm{mg} / \mathrm{kg}$ of body weight. Hence the effective doses were fixed as 200 and $400 \mathrm{mg} / \mathrm{kg}$ for further pharmacological studies.

\section{Uterotonic activity study}

The study revealed that both doses of EECP inhibited the process of implantation. The same has been depicted in Table 2. The loss of implantation caused may be due to antizygotic, blastocytotoxicity, as well as anti-implantation activity. ${ }^{25}$ During the study of haematological parameters a statistically non-significant change in the RBC, WBC, haemoglobin content were observed in the antiimplantation group of rats after administration of the EECP at $200 \mathrm{mg} / \mathrm{kg}$ and EECP at $400 \mathrm{mg} / \mathrm{kg}$ of body weight respectively when compared with the control groups. The results are depicted in Table 3. The biochemical 


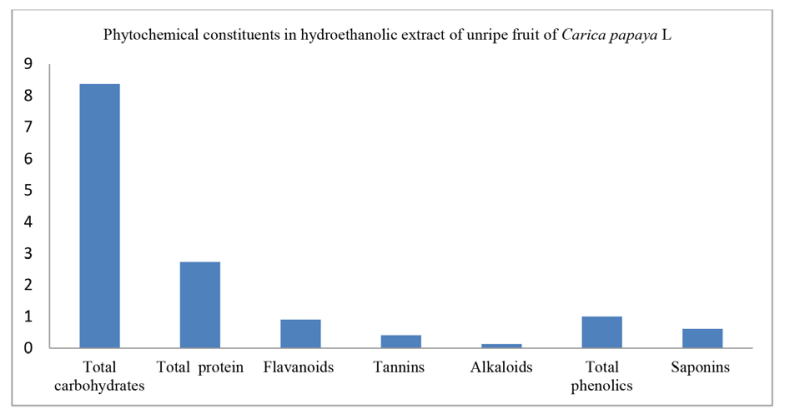

Units: Total Carbohydrates -grams/100 grams; Total Protein- grams/100 grams; Flavanoids - Quercetin equivalent(QE); Tannins- Tannic acid equivalent (TAE); Alkaloids: gallic acid equivalent (GAE); Total phenolics gallic acid equivalent

Figure 1: Phytochemical constituents in hydroethanolic extract of unripe fruit of Carica papaya L

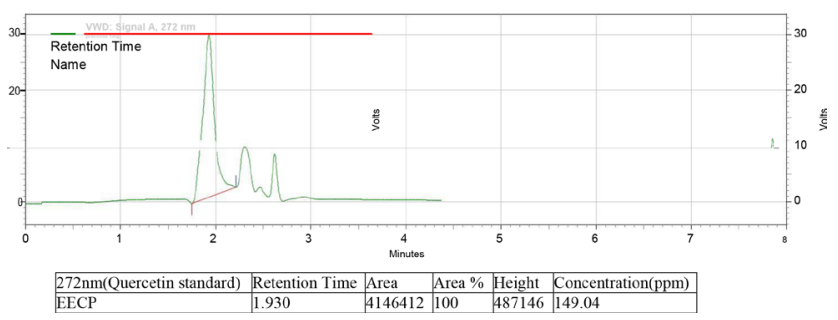

Figure 2 : HPLC analysis to recognize flavanoid compounds in EECP

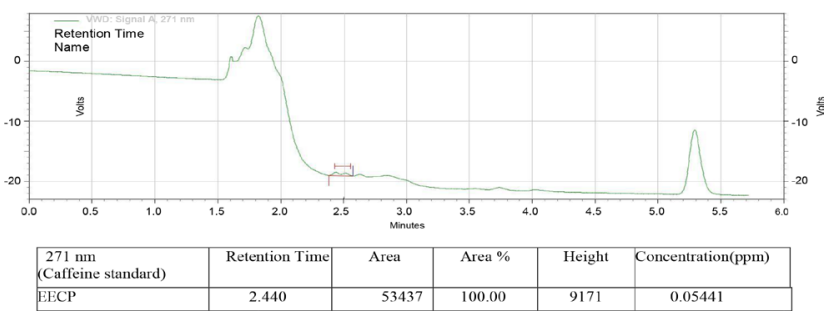

Figure 3 : HPLC analysis to recognize alkaloid compounds in EECP

Table 1: Phytochemical analysis of the extract

\begin{tabular}{|c|c|}
\hline Plant constituents & Extract \\
\hline Carbohydrate & + \\
\hline Protein & + \\
\hline Fixed oil & - \\
\hline Steroid & - \\
\hline Alkaloid & + \\
\hline Flavanoid & + \\
\hline Phenol & + \\
\hline Saponin & + \\
\hline Glycoside & + \\
\hline Tannin & + \\
\hline
\end{tabular}

+: Present -:Absent parameters were studied and the results are depicted in Table 4. During the investigation the glucose concentration was not significantly altered in EECP treated group of animals when compared with the control and they were within the normal range. The cholesterol concentration was increased after EECP administration indicating non utilization of cholesterol by the system. The triglycerides concentration was increased after EECP administration indicating non utilization of triglycerides by the system. In the present study, an increase in alkaline phosphatase was observed in both low and high dose of EECP treated animals. The level of SGOT and SGPT are commonly used as a way of screening for liver anomalies. SGOT and SGPT are raised in acute liver damage. A statistically non-significant change in the SGOT and SGPT values were observed in groups II and III after administration of the EECP at a dose of $200 \mathrm{mg} / \mathrm{kg}$ and $400 \mathrm{mg} / \mathrm{kg}$ of body weight treated rats respectively when compared with control groups. Both the values were found within the normal range. This indicates that EECP have no toxic effect on liver, biliary system, and pancreas.

\section{Study of alteration in hormone levels}

The assessment of the abortifacient activity was performed. The results showed that EECP EECP significantly affects on the stability of the hormones that maintain pregnancy. After the extracts were given, the level was altered significantly in all groups. The pregnancy of Group II and III were terminated successfully. The rats of Group I (Control) delivered pups without any malformation.

\section{Effect of EECP on $\beta$-hCG}

During the screening of hormone levels in various groups (Table 5), it was observed that the $\beta$-hCG level decreased on day 21 and is statistically significant. This is due to the fact that the level of this hormone would decrease after the first trimester even when the pregnancy persist. In group II, III and IV there was a decrease in the hormone level on day 21. This may be due to the action of the extract on the hormone stability.

\section{Effect of EECP on progesterone}

It was inferred from Table-6 that the level of the hormone on day 10 and day 21 showed significant differences. In group I(control) it was observed that the progesterone level increased on day 21 and is statistically significant. This is due to the fact that the level of this hormone would increase during the period of pregnancy. In all other groups, only a slight increase in the 


\begin{tabular}{|c|c|c|c|c|c|}
\hline \multicolumn{7}{|c|}{ Table 2: Anti-implantation activity of EECP in female rats } \\
\hline Group & Treatment & $\begin{array}{c}\text { No. of } \\
\text { pregnancies }\end{array}$ & $\begin{array}{c}\text { Number of } \\
\text { implantation sites }\end{array}$ & $\begin{array}{c}\text { Total No of } \\
\text { litters }\end{array}$ & Average \\
\hline I & Group I (Control) & $6 / 6$ & $7,6,9,6,9,8$ & 51 & 7.5 \\
\hline II & $\begin{array}{c}\text { Group II } \\
\text { (EECP 200 mg/kg p.o) }\end{array}$ & $6 / 6$ & $5,3,5,4,2,3$ & 22 & 3.6 \\
\hline III & $\begin{array}{c}\text { Group III } \\
\text { (EECP 400 mg/kg p.o) }\end{array}$ & $4 / 6$ & $2,1,0,0,2,1$ & 6 & 1 \\
\hline IV & $\begin{array}{c}\text { Group IV } \\
\text { (standard ethinyl estradiol 0.02mg/kg p.o.) }\end{array}$ & $0 / 6$ & - & - & - \\
\hline
\end{tabular}

\begin{tabular}{|c|c|c|c|c|}
\hline \multicolumn{2}{|c|}{ Table 3: Haematological parameters of EECP (Uterotonic activity) } \\
\hline Parameters & $\begin{array}{c}\text { Group I } \\
\text { (Control) }\end{array}$ & $\begin{array}{c}\text { Group II } \\
\text { (EECP 200 mg/kg) }\end{array}$ & $\begin{array}{c}\text { Group II } \\
\text { (EECP 400 mg/kg) }\end{array}$ & $\begin{array}{c}\text { Group IV } \\
\text { (Ethinyl estradiol 0.02mg/ } \\
\text { kg) }\end{array}$ \\
\hline RBC $\left(\times 10^{6} \mu \mathrm{L}^{-1}\right)$ & $7.65 \pm 0.21$ & $8.72 \pm 0.18$ & $8.96 \pm 0.24$ & $8.70 \pm 0.23$ \\
\hline WBC $\left(\times 10^{6} \mu \mathrm{L}^{-1}\right)$ & $8.86 \pm 0.31$ & $9.27 \pm 0.09$ & $9.76 \pm 0.74$ & $8.91 \pm 0.33$ \\
\hline Haemoglobin $(\mathrm{g} / \mathrm{dL})$ & $12.45 \pm 0.72$ & $13.34 \pm 0.15$ & $13.82 \pm 0.48$ & $12.60 \pm 0.54$ \\
\hline HT $(\%)$ & $41.17 \pm 0.21$ & $40.27 \pm 1.77$ & $42.49 \pm 1.80$ & $42.11 \pm 0.12$ \\
\hline
\end{tabular}

Values are Mean $\pm S D(n=6$ in each group).

\section{Table 4: Biochemical parameters of administration of varying concentrations of EECP}

\begin{tabular}{|c|c|c|c|c|c|}
\hline \multirow[b]{2}{*}{ S. No. } & \multirow[b]{2}{*}{ Parameters } & \multicolumn{4}{|c|}{ Groups } \\
\hline & & Group I (Control) & $\begin{array}{c}\text { Group II } \\
\text { (EECP 200mg/ } \\
\text { kg.po) }\end{array}$ & $\begin{array}{l}\text { Group III } \\
\text { (EECP 400mg/ } \\
\text { kg.po) }\end{array}$ & $\begin{array}{c}\text { Group IV } \\
\text { (Ethinyl estradio } \\
0.02 \mathrm{mg} / \mathrm{kg} \text { ) }\end{array}$ \\
\hline & Blood glucose (mg/dL) & $129.85 \pm 9.13$ & $125.60 \pm 7.85$ & $122.42 \pm 9.20$ & $125.35 \pm 8.21$ \\
\hline & Cholesterol (mg/dL) & $60.80 \pm 6.20$ & $74.35 \pm 2.45^{*}$ & $135.75 \pm 6.29^{* *}$ & $141.32 \pm 6.29^{* *}$ \\
\hline & Triglycerides(mg/dL) & $105.26 \pm 5.5$ & $141.21 \pm 6.62^{* *}$ & $169.35 \pm 4.65^{\star *}$ & $178.39 \pm 6.77^{\star \star}$ \\
\hline & Alkaline Phosphatase (IU/L) & $107.11 \pm 2.72$ & $121.52 \pm 1.23$ & $137.70 \pm 2.24^{* * *}$ & $148.20 \pm 2.38^{* * *}$ \\
\hline & SGOT (IU/L) & $75.00 \pm 8.27$ & $79.12 \pm 0.20$ & $80.28 \pm 2.90$ & $81.30 \pm 3.92$ \\
\hline & SGPT (IU/L) & $48.60 \pm 2.46$ & $41.22 \pm 2.38$ & $47.58 \pm 2.38$ & $41.51 \pm 2.43$ \\
\hline
\end{tabular}

Values are Mean $\pm S D(n=6$ in each group)

$* P<0.05$ when compared with the control

$* * P<0.01$ when compared with the control

$* * * P<0.001$ when compared with the control

hormone level on day 21 was noted which is statistically not significant. This may be due to the action of the extract on the hormone stability which would in turn lead to termination of pregnancy.

\section{Effect of EECP on estradiol}

It is inferred from Table 7 that statistical analysis was carried out for estradiol for each group between day 10 and day 21. This is due to the fact that the level of this hormone would increase during the gestation period which in turn helps to maintain pregnancy. In groups II,III and IV drastic variation was observed on day 21. This may be due to the action of the extract on the hormone stability due to which the termination of pregnancy takes place.

\section{DISCUSSION}

The study revealed that both doses of EECP inhibited the process of implantation. It is well known that for implantation, exact equilibrium of estrogen and progesterone hormone level is essential and any disturbance in the level of these hormones may cause infertility ${ }^{26}$. The compound of hormonal values usually disturbs the hormonal milieu in the uterus and provokes antifertility effect. Therefore, the antiimplantation activity 
Table 5: Level of Human Chorionic Gonadotropin on Day 10 and Day 21

\begin{tabular}{|c|c|c|}
\hline \multirow{2}{*}{ Groups } & \multicolumn{2}{|c|}{ Level of $\boldsymbol{\beta}$ - HCG in $\mathrm{mIU} / \mathrm{ml}$} \\
\cline { 2 - 3 } & Day 10 & Day21 \\
\hline Groupl(Control) & $2.017 \pm 0.147$ & $0.617 \pm 0.117^{* *}$ \\
\hline Group II (EECP 200mg/kg.po) & $1.950 \pm 0.187$ & $0.483 \pm 0.041^{* *}$ \\
\hline Group III(EECP 400mg/kg.po) & $1.150 \pm 0.084$ & $0.533 \pm 0.082$ \\
\hline Group IV(Ethinyl estradiol 0.02mg/kg) & $0.500 \pm 0.089$ & $0.489 \pm 0.021$ \\
\hline
\end{tabular}

Values are Mean $\pm S D$ ( $n=6$ in each group)

$* \mathrm{P}<0.05$ when compared with day 10

$* * \mathrm{P}<0.01$ when compared with day 10

\begin{tabular}{|c|c|c|}
\hline \multicolumn{2}{|c|}{ Table 6: Level of Progesterone on Day 10 and Day 21 } \\
\hline Groups & \multicolumn{2}{|c|}{ Level of Progesterone in $\mathbf{~ n g} / \mathbf{m l}$} \\
\cline { 2 - 3 } & Day 10 & Day21 \\
\hline Groupl(Control) & $15.083 \pm 0.875$ & $20.550 \pm 0.509^{* *}$ \\
\hline Group II (EECP 200mg/kg.po) & $5.917 \pm 0.380$ & $8.032 \pm 0.654^{*}$ \\
\hline Group III(EECP 400mg/kg.po) & $1.642 \pm 0.174$ & $2.505 \pm 0.448^{\star *}$ \\
\hline Group IV(Ethinyl estradiol 0.02mg/kg) & $1.533 \pm 0.103$ & $0.348 \pm 0.105^{\star *}$ \\
\hline
\end{tabular}

Values are Mean $\pm S D(n=6$ in each group)

$* \mathrm{P}<0.05$ when compared with day 10

$* * P<0.01$ when compared with day 10

Table 7: Level of Estradiol on Day 10 and Day 21

\begin{tabular}{|c|c|c|}
\hline \multirow{2}{*}{ Table 7: Level of Estradiol on Day 10 and Day 21 } \\
\hline \multirow{2}{*}{ Groups } & \multicolumn{2}{|c|}{ Level of estradiol in pg/ml } \\
\cline { 2 - 3 } & Day $\mathbf{1 0}$ & Day21 \\
\hline Groupl(Control) & $5.283 \pm 0.279$ & $10.317 \pm 0.685^{* *}$ \\
\hline Group II (EECP 200mg/kg.po) & $5.033 \pm 0.391$ & $19.30 \pm 0.562^{\star *}$ \\
\hline Group III(EECP 400mg/kg.po) & $5.083 \pm 0.147$ & $22.027 \pm 0.572^{* *}$ \\
\hline Group IV(Ethinyl estradiol 0.02mg/kg) & $5.850 \pm 0.187$ & $50.983 \pm 0.595^{\star *}$ \\
\hline
\end{tabular}

Values are Mean $\pm S D(n=6$ in each group)

$* \mathrm{P}<0.05$ when compared with day 10

$* * P<0.01$ when compared with day 10

may be due to increased estrogenic activity, causing the expulsion of ova from the tube, disturbing the luteotrophic activity of the blastocyst..$^{27,28}$ In the present study, both the doses of EECP exhibited anti-implantation and abortifacient properties. This result agreed with the finding of Badami et al., ${ }^{29}$ who reported that oral administration of ethanol extract of the powdered root of Derris brevipes variety coriacea showed both abortifacient and antiimplantation effects in rats. Since a statistically non-significant change in the RBC, WBC, haemoglobin content were observed in all the groups after administration of the EECP at $200 \mathrm{mg} / \mathrm{kg}$ and EECP at $400 \mathrm{mg} / \mathrm{kg}$ of body weight respectively when compared with the control group, it indicates that the EECP have no toxic effect on haematological parameters. During the study of biochemical parameters the glucose concentration was not significantly altered in EECP treated group of animals when compared with the control and they were within the normal range. The cholesterol and triglycerides concentrations were altered after EECP administration indicating non utilization of cholesterol by the system. Hence the investigation suggests that EECP treatment exerts estrogenic activity, in female rats. It is well established that alkaline phosphatase is associated with the decidual cell reaction and play important role in implantation. In the present study, increase in alkaline phosphatase was observed in both doses of EECP treated animals. The precise role of phosphatases in the process of implantation still needs proper understanding although, it would be premature to correlate the changes in the uterine phosphatases and anti-implantation effect of test substances but the alteration in the activity of the uterine phosphatases could conjecturally be playing a role in the prevention of pregnancy. ${ }^{30}$ 
A statistically non-significant change in the SGOT and SGPT values were observed in the anti-implantation group of rats after administration of the EECP at a dose of $200 \mathrm{mg} / \mathrm{kg}$ and $400 \mathrm{mg} / \mathrm{kg}$ of body weight respectively when compared with control groups. Both the values were found within the normal range. This indicates that EECP have no toxic effect on liver, biliary system, and pancreas. In the study it was noticed that there is significant difference in the level of $\beta$-hCG because after the first trimester the level of this hormone returns to the normal level even when the pregnancy persists. ${ }^{31}$ In the treated groups significant variation was observed on day 21 in the level of progsterone. This in turn had affected the stability of pregnancy. In group II, III and IV drastic variation was observed on day 21 in the level of estradiol. This may be due to the action of the extract on the hormone stability which would in turn lead to termination of pregnancy. The loss of the foetus caused by the extracts may be due to their anti implantation activity. ${ }^{32}$

The present investigation has shown that papaya latex has oxytocic properties similar to the in vitro effects of oxytocin and prostaglandin F2a in pregnant and nonpregnant rat uterus. This suggests that crude papaya latex could be a potential abortifacient.

\section{CONCLUSION}

The present study revealed that the hydroethanolic fraction of unripe fruit of C. papaya $\mathrm{L}$ has pronounced uterotonic effect on the hormonal levels of $\beta$-hCG, progesterone and estradiol which are vital for maintaining pregnancy. The biochemical parameters also showed significant variations.

\section{CONFLICT OF INTEREST}

The authors declare that there are no conflicts of interest.

\section{ACKNOWLEDGEMENT}

We express our heartfelt thanks to Dr.Jaslin Edward, Managing Director, Cape Bio lab \& Research centre, Marthandam, for the lab facilities provided for the work.

\section{ABBREVIATIONS USED}

EECP: Hydroethanolic extract of Carica papaya L.; $\beta$-hCG: $\beta$-human Chorionic Gonadotropin; SGPT: Serum glutamic pyruvic transaminase; SGOT: Serum glutamic oxaloacetate transaminase; HT: Haematocrit.

\section{REFERENCES}

1. Ghosh K, Bhattacharya TK. Preliminary study on the anti-implantation activity of compounds from the extracts of seeds of Thespesia populnea. Indian Journal of Pharmacology2004;36(5): 288-291.

2. Aitken RJ, Baker MA, Doncel GF,Matzuk MM, Mack CK, Harper JK. As the world grows: contraception in the 21st century. Journal of Clinical Investigation, 2008; 118(4):1330-143.

3. Chauhan A, Agarwal M, Kushwaha S, Mutreja A. Antifertility studies of Aegle marmelos Corr: an Indian medicinal plant on male albino rat. Egyptian Journal of Biology,2008;10: 28-35

4. Negi AS, Dwivedi I,Setty BS, Ray S. Benzophenones, naphthophenones and related compounds as spermicidal agents. Indian Journal of Pharmaceutical Sciences, 1994;56(3): 105-8.

5. Bagul MS, Kanaki NS, Rajani M. Evaluation of free radical scavenging properties of two classical polyherbal formulations. Indian Journal of Experimental Biology,2005;43(8): 732-36.

6. Umadevi M, Sampath Kumar PK, Debjit Bhowmik, Duraivel S. Medicinal Plants with Potential Antifertility Activity. Journal of Medicinal Plants Studies, 2013;1(1):26-33.

7. Gallo M, Sarkar M, Smith M.Pregnancy outcome following gestational exposure to echinaceae: A prospective controlled study. Archives of internal Medicine,2000;160: 3141-43.

8. Anjum V, Ansari SH, Naquvi KJ, Arora P, Ahmad A. Development of quality standards of Carica papaya Linn.Leaves. Sch Res Lib 2013; 5(2):370-76.

9. Schmidt $\mathrm{H}$. Effect of papain on different phases of prenatal ontogenesis in rats. Reproductive Toxicology, 1995; 9: 49-55.

10. Adebiyi A, Adaikan PG, Prasad RN. Papaya (Carica papaya) consumption is unsafe in pregnancy, fact or fable? Scientific evaluation of a common belief in some parts of Asia using a rat model. Br J Nutr,2002; 88(2):199-203.

11. Krishna KL, Paridhavi M, Patel JA. Review on nutritional and pharmacological properties of papaya (Carica papaya Linn). Nat Prod. Radian, 2008; 7:364-73

12. Cherian $\mathrm{T}$. Effect of papaya latex extract on gravid and non-gravid rat uterine preparations in-vitro. J Ethnopharmacol, 2000;70(3):205-12.

13. Atta $\mathrm{K}$ Bonsu. The Power of Garlic. Cardiovascular disease prevention Association, Buea, Cameroon.1999. p.72.

14. Okwu DE, Okwu ME. Chemical composition of Spondia mombin plants. J. Sustain Agric. Environ 2004;6: 140-47.

15. Bakhru HK, Nature cure for cancer. First edition, Delhi, Jaico Publishing House,;2008:1-2

16. Oderinde $\mathrm{O}$, Norohna $\mathrm{C}$, Oremosu A. Abortifacient properties of aqueous extract of Carica papaya (Linn) seeds on female Sprague-Dawley rats. Niger post graduate medical journal. 2002; 9(2),95-98.

17. Sani Ali Audu, Ilyas Mohammed, Haruna Abdual Kaita. Phytochemical screening of the leaves of Lophira lanceolate (Ochanaceae). Life Science Journal 2007;4(4):75-79.

18. Kokate CK . Practical pharmacognosy. $4^{\text {th }}$ edition. Delhi: Vallabh prakashan.1994,8-30.

19. Gebrie E, Makonnen E, Debella A, Zerihun L. Phytochemical screening and pharmacological evaluations for the antifertility effect of the methanolic root extract of Rumex steudelii. Journal of Ethnopharmacology. 2005;96: 139-143.

20. Abdelouaheb Djilani,Belgacem Legseir,Rachid Soulimani,Amadou Dickob and ChaffiqueYounos. New Extraction Technique for Alkaloids. J. Braz. Chem. Soc.,2006; Vol. 17, No. 3; 518-520, 2006.

21. Trease GE, Evans WC. Pharmacognosy, 15th ed. Philadelphia: W.B. Saunders, Elsevier Science Limited; 2002. p. 471

22. Eluyode O S,Alabi OS. Preliminary phytochemical screening of crude extracts of Commiphora. africana on inflammation and pain in rodents. Africana on inflammation and pain in rodents. Asi. J. Med. Sci 2007;2(3):81-84.

23. Ecobichon DJ. The basis of toxicology testing. 2nd ed., CRC press, New york. 1997, $43-60$

24. Khanna U, Chaudhury RR. Antifertility screening of plants part. Indian J. Med. Res 1968; 56:1575-9.

25. Hafez. E.S.E Reproduction in breeding techniques for laboratory animals. Lea and Febiger, Philadelphia; 1970.

26. Psychoyos, A. Recent Research on Egg Implantation, Ciba Foundation Study Group on Egg Implantation. Churchill, London, UK: 1966; 4-28.

27. Pincus, G. Control of Fertility. Academic Press, New York:1965. 
28. Anderson LL. Biology of Mammalian Fertilization and Implantation. IL: Thomas Springfield; 1972.

29. Badami S, Aneesh R, Sanker S, Satishkumar MN, Suresh B, Rajan S. Antifertility of Derris brevipes variety coriacea. J.Ethnopharmacol. 2003; 84(1): 99-104.

30. Gupta $P$, Mathu. Changes in the uterine phosphatase levels in female Swiss albino mice treated with chromatographic fractions of petroleum ether extracts of Vinca rosea leaves. J Herbal Medicine and Toxicology, 2009; 3(2): 143- 145 .

31. Jacques Wallach. Handbook of Interpretation of Diagnostic Tests.. Philadelphia, PA: Lippincott-Raven Publishers; 1998, 564

32. Hafez E.S.E. Reproduction and Breeding Techniques for Laboratory Animals. Pheladelphia ,Lea and Febiger;1970 .1-4.

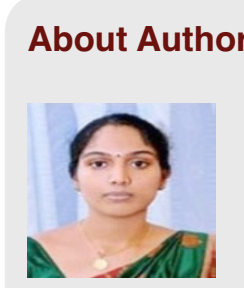

Mrs. P Praveena: Is presently working as Assistant Professor, Department of Biotechnology, Sahrdaya college of Engineering and Technology, Thrissur, Kerala. Currently she is pursuing her Ph.D from Department of Biochemistry, Research and Development Centre, Bharathiar University, Coimbatore, Tamil Nadu, India, under the guidance of DR. D Victor Arokia Doss. Her major research area and publications are in the field of Biochemistry, Clinical toxicology and Phytochemistry and Pharmacology.

\section{SUMMARY}

- The unripe fruit of Carica papaya $L$ were taken for the present study.

- The hydro-ethanolic extract was prepared and the phytochemicals were analyzed.

- The extract was tested for uterotonic property using Wistar albino rats. After administration of the extracts, antiimplantation property, haematological as well as biochemical parameters were screened.

- The present study revealed that the hydro-ethanolic fraction of unripe fruit of C.papaya L has pronounced uterotonic effect.

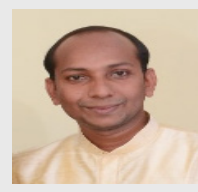

Mr. Jethinlalkhosh JP: Is working as Quality Control Assistant in Food Corporation of India, Trivandrum, Kerala, India. Prior to that, he worked as an Assistant Professor, Department of Biotechnology and Applied Microbiology, St. Thomas College, Pala, Kottayam, Kerala, India. Currently he is pursuing his Ph.D from Department of Biochemistry, Research and Development Centre, Bharathiar University, Coimbatore, Tamil Nadu, India, under the guidance of DR. D Victor Arokia Doss. He is having research experience in the field of Phytochemistry, Pharmacology, Clinical Biochemistry and Toxicology, Molecular Biology and Cancer Biology and is having publications in many international peer reviewed journals.

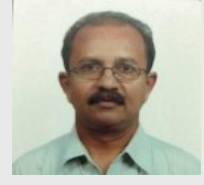

Dr. Victor Arokia Doss: Is working as an Associate Professor in the Department of Biochemistry, P S G Arts and Science College, Coimbatore, Tamil Nadu, India since 1994. He has research experience in the field of Clinical Biochemistry and Toxicology, Molecular Biology, Cancer Biology, Immunology, Protein Chemistry and Bioinformatics. Over the years he has authored and coauthored more than 80 research articles in international peer reviewed journals.

Cite this article: Praveena P, Jethinlalkhosh JP, Doss VA. Evaluation of uterotonic activity of hydroethanolic extract of unripe fruit of Carica papaya Linn using Wistar albino rats. Indian $\mathrm{J}$ of Pharmaceutical Education and Research. 2017;51(4S):S615-S22. 